\title{
Impasses e oportunidades para a construção de um Sistema Regional de Inovação no Grande ABC
}

\author{
Impasses and opportunities in the construction \\ of a regional innovation system in Greater ABC
}

Roberto Vital Anau [l]

\section{Resumo}

0 artigo trata das oportunidades e desafios para a construção de um Sistema de Inovação Regional no Grande ABC Paulista, subconjunto de sete municípios da Região Metropolitana de São Paulo. A partir da caracterização dos traços fundamentais da região, de sua história recente e de seus dados econômicos, resgata-se o esforço da primeira década e meia do século XXI com vistas à citada construção. Com base nos elementos colhidos em pesquisa estatística, documental e de entrevistas, identificam-se os pontos fortes e as lacunas do processo. Conclui-se com elenco de sugestões para a revitalização daquele esforço, sob novas diretrizes e novo arranjo de governança da instituição incumbida do fortalecimento da economia regional - a Agência de Desenvolvimento Econômico do Grande ABC.

Palavras-chave: sistema regional de inovação; Região do Grande $A B C$; desenvolvimento econômico regional; inovação, modernização e diversificação econômica regional; Agência de Desenvolvimento Econômico do Grande ABC.

\begin{abstract}
The article deals with the opportunities and challenges related to the construction of a Regional Innovation System in Greater $A B C$, a subset of seven municipalities in the Metropolitan Region of São Paulo. Starting with a characterization of the fundamental features of the region, its recent history and economic data, the effort of the first fifteen years of the 21st century to carry out the aforementioned construction are revisited. Based on the elements collected in a statistical, documentary research and through interviews, the strengths and weaknesses of the process are identified. It concludes with a list of suggestions for revitalizing that effort, under new guidelines and a new governance arrangement of the institution responsible for strengthening the regional economy - the Economic Development Agency of Greater $A B C$.
\end{abstract}

Keywords: regional innovation system; Greater $A B C$ Region; regional economic development; regional economic innovation, modernization and diversification; Economic Development Agency of Greater $A B C$. 


\section{Introdução}

Este artigo elenca impasses e oportunidades atuais para o desenvolvimento de um Sistema de Inovação Regional no Grande $A B C$, cujo instrumento histórico tem sido a Agência de Desenvolvimento Econômico do Grande $A B C$ (ADE-GABC).

A relevância e a oportunidade do tema relacionam-se à presente crise vivenciada por essa entidade, criada nos anos 1990 para impulsionar a inovação e o fortalecimento produtivo da região do Grande $A B C$. Crise que expressa, sem dúvida, o impacto do cenário macroeconômico negativo do triênio recém-encerrado, mas também impasses mais antigos da própria região, explanados nas seções a seguir. A dimensão atual dessa crise chega a pôr em risco a continuidade da instituição, segundo um de seus mais assíduos componentes, o bloco dos principais sindicatos da região. ${ }^{1}$ Trata-se de território paradigmático da industrialização brasileira, do sindicalismo mais atuante do País, de forte presença acadêmica e de histórico de articulação entre esses atores e o Poder Público local.

A base empírica do artigo é pesquisa realizada para tese de doutorado realizada na Universidade Federal do $A B C$, no programa de Planejamento e Gestão do Território (Anau, 2017).

A referida pesquisa valeu-se de estatísticas econômicas regionais, análise documental e entrevistas com quatorze atores regionais relevantes no período 2000-2015, sendo cinco empresários, dois dos quais ligados a montadoras, um a autopeças, um representante do polo petroquímico e um ex-diretor de associação comercial; três sindicalistas, ligados às categorias metalúrgica, química e bancária; um prefeito e presidente do consórcio intermunicipal; um consultor, que coordenou projeto estratégico da agência; e quatro docentes. Grande parte exerceu funções de destaque nas instituições de articulação regional.

0 tratamento dessas informações baseou-se nos referenciais teóricos do neoschumpeterianismo e da escola britânica da regulação.

A seguir, sintetizam-se os principais resultados da pesquisa. A seção 2 resume os paradigmas teóricos adotados, sua coerência entre si e com a temática da pesquisa. A seção 3 apresenta a história recente da região, destacando seus traços marcantes e especialmente o esforço de articulação regional dos últimos 25 anos. Na seção 4, apresentam-se os aspectos centrais do diagnóstico do Grande $A B C$, focado na economia e na inovação, cabendo à seção 5 apresentar os esforços realizados no sentido de articulá-las. Por fim, a seção 6 apresenta possibilidades concretas de reorganização e redefinição estratégica da $A D E-G A B C$, à guisa de sugestões, em face dos agudos desafios presentes.

\section{0 arcabouço teórico}

As informações levantadas foram interpretadas com base na teoria evolucionária ou neoschumpeteriana (Nelson e Winter, 2005; Freeman e Soete, 2008) e na Escola da Regulação, mormente em sua vertente britânica. Da primeira, extraiu-se, particularmente, o conceito de Sistema Regional de Inovação (SRI), derivação do conceito de Sistema Nacional de Inovação (SNI): 
O SNI é um sistema aberto, evolutivo e complexo que compreende relações dentro e entre organizações, instituições e estruturas socioeconômicas, que determina a taxa e a direção da inovação e da construção de competência e que emana de experiências de aprendizado baseado em ciência e em experiência. (Lundvall et al., 2013, p. 9; tradução nossa) ${ }^{2}$

Da segunda vertente, adotou-se a interpretação do território como espaço de disputa, combinando contraditoriamente múltiplas escalas territoriais imbricadas. Nesse enfoque, as escalas não circunscrevem meramente as relações sociais dentro de fronteiras geográficas determinadas, mas constituem um momento ativo, socialmente produzido e politicamente contestado dessas relações (Jessop, 2000; Brenner, 2010; Brenner e Theodore, 2003).

Ambos os arcabouços teóricos adotados dialogam entre si e com a temática da pesquisa. A vertente neoschumpeteriana é útil ao entendimento e à ação sobre a realidade mutável do capitalismo por, pelo menos, três razões: (1) destaca o papel motor da inovação; (2) insiste no papel da incerteza e na inexistência de uma estratégia ótima; (3) apresenta caminhos possíveis para o desenvolvimento tecnológico e econômico dos países emergentes. $A$ compreensão do caráter dinâmico e transformador do capitalismo é outra vantagem dessa vertente teórica, em contraposição à análise estática do equilíbrio neoclássico.

Também são relevantes os estudos, registros e conclusões sobre a importância da atuação do Estado, no sentido de reforçar vantagens e fatores propícios ao desenvolvimento nacional e regional.
Por fim, no tocante aos Sistemas de Inovação, é extremamente positiva a contribuição dos autores neoschumpeterianos. A narrativa de Freeman e Soete (2008) sobre os Sistemas Nacionais de Inovação aproxima-se de um objeto mais concreto e, ao fazê-lo, oferece um quadro histórico e conceitual bastante operacional para qualquer pesquisa sobre Sistemas de Inovação específicos, mesmo subnacionais. Elementos-chave de um Sistema de Inovação são descritos em sua historicidade e atuação conjunta, em casos emblemáticos, inclusive para análises comparativas.

Quanto ao arcabouço regulacionista, não resta dúvida de que ele possibilitou uma compreensão renovada e realista sobre os mecanismos históricos de mudança e adaptação do capitalismo às crises que constituem a essência da dinâmica capitalista. A versão britânica da escola regulacionista, por sua vez, agrega um componente da maior importância na era histórica da globalização neoliberal: o espaço, acoplado à temporalidade. Dessa forma, ela permite abordar de forma mais criativa os processos de redefinição espacial da acumulação de capital, apresentando um cenário mais rico de múltiplos espaços e territórios em disputa e/ ou em cooperação (principalmente em termos interescalares), com seus atores internos também atuando, ora em sintonia, ora em conflito, na busca pelos capitais altamente móveis.

Essa abordagem é de grande utilidade ao tema da pesquisa em foco: potencialidades e limites de Sistemas Regionais de Inovação (SRI). Deve-se dizer que o tema da inovação e dos próprios Sistemas de Inovação é plenamente integrável ao arcabouço regulacionista, e muitos de seus teóricos o abordam, 
embora lateralmente. A constituição de SRI não estabelece mero arranjo técnico ou de política pública "neutra", mas compõe uma agenda de disputa intra e inter-regional - e mesmo nacional e global. Daí sua compatibilidade com a teoria em foco.

Dessa forma, embora possuam quadros de referência distintos entre si, ambas as bases teóricas adotadas dialogam entre si e com o tema da pesquisa, possibilitando interpretações frutíferas. Na tese originadora do presente artigo, busca-se submetê-las à crítica, identificando suas limitações, sem todavia desqualificá-las enquanto quadros de referência úteis. Apresenta-se, também, na referida tese, sugestão adicional de referência teórica e de tema de pesquisa complementar, que não cabe reproduzir nos limites deste artigo (Anau, 2017, capítulo 1 e conclusão).

\section{Grande $A B C$ - traços marcantes e história recente}

A região do Grande $A B C$ constitui um conjunto de sete municípios localizados na porção sudeste da Região Metropolitana de São Paulo: Diadema, Mauá, Ribeirão Pires, Rio Grande da Serra, Santo André, São Bernardo do Campo e São Caetano do Sul. Trata-se de região bastante conhecida, no âmbito nacional, por três atributos, entre outros, de sua história no Século XX. 0 primeiro é seu parque industrial, que constitui a maior aglomeração industrial da América Latina, focada no setor automotivo e respectiva cadeia produtiva, e é complementado pela petroquímica, com ramificações a montante (a Refinaria de Capuava) e a jusante (os segmentos químico, plástico e alguns outros).

0 decorrente processo de urbanização, com crescimento dos serviços, teve como uma de suas características o desenvolvimento de expressiva rede regional de ensino superior. Também se destaca a rede de ensino técnico. Esses ativos educacionais são fatores regionais emblemáticos, induzidos pela existência do forte polo industrial citado, ao longo de sua história.

Outro destaque econômico é o turismo, que inclui as regiões de mananciais da represa Billings, porções da Serra do Mar, rotas gastronômicas, sítios históricos e alguns parques públicos mais conhecidos.

0 segundo elemento-chave que identifica o Grande $A B C$ nacional e internacionalmente, desde o início dos anos 1970, é seu forte sindicalismo. Nos anos 1980, este teve atuação decisiva nos embates contra o regime militar e na reorganização sindical e partidária do País. Nas décadas seguintes, manteve importância central (Rodrigues, Ramalho e Conceição, 2009), até a conquista da Presidência da República por sua mais expressiva liderança, abrindo um período de 13 anos de um novo desenvolvimentismo, com distribuição de renda inédita nas quatro décadas anteriores - ainda que eivado de contradições e limitações.

Por último, mas igualmente importante, as instituições de articulação regional, públicas ou de composição público-privada, criadas durante os anos 1990, também chamaram a atenção de inúmeros observadores em âmbito nacional e até de alguns pesquisadores da organização territorial em outros países (Klink, 2000; 2001; 2003; 2011). Além do âmbito institucional, esse processo também se expressa em 
termos políticos, sociais e até mesmo culturais, como se percebe na força de um sentimento difuso de pertencimento à região. Em termos institucionais, das diversas organizações que emergiram nesse processo, permanecem em atividade o Consórcio Intermunicipal Grande $A B C$ e a Agência de Desenvolvimento Econômico do Grande ABC (ADE-GABC).

Esses dois organismos da regionalidade buscaram complementar suas ações - o primeiro, reunindo institucionalmente os sete prefeitos para uma atuação, ao mesmo tempo, entre si e junto às esferas estadual e federal, em diversas políticas públicas; o segundo, visando ao fortalecimento da economia regional, rumo a um sistema regional de inovação e aprendizagem, por meio da articulação entre o poder público local, o empresariado, os sindicatos e as universidades.

Visivelmente, a ação do Consórcio foi mais efetiva. Ações voltadas à infraestrutura e à interação de algumas políticas sociais lograram sucessos expressivos, ainda que parciais. Em anos recentes, produziu-se também 0 , até então inédito, Plano Plurianual Regional Participativo para o período 2014-2017. Quanto às ações da Agência, sua eficácia e efetividade foram bem mais reduzidas no cenário econômico da região.

\section{Economia regional e inovação: os desafios permanecem}

Os levantamentos estatísticos realizados abrangeram o PIB dos municípios, o Valor Adicionado Fiscal, o comércio exterior e o emprego, todos discriminados por município, abertos em subcategorias e agregados regionalmente (Anau, 2017, pp. 141-265). De maneira geral, os dados mostram a permanência do peso excessivo das duas cadeias produtivas estruturantes da economia regional, supracitadas. As vicissitudes dessas cadeias afetam poderosamente os indicadores de emprego, renda e qualidade de vida da maioria da população dos sete municípios consorciados. As oscilações sofridas por esse agrupamento de atividades econômicas até o presente demonstram a fragilidade de boa parte dos segmentos econômicos existentes, em termos de inovação e de diversificação de mercados. Fortemente vinculados aos segmentos-líderes no topo das respectivas cadeias, tais segmentos não conseguiram ampliar seus mercados consumidores de forma a sofrer menores impactos das conjunturas estritas daqueles segmentos líderes. Ademais, alguns desses níveis (ou tiers) das redes de suprimento têm perdido competitividade ante produtos importados, que apresentam mais vantagens tecnológicas, de custos ou de velocidade de atendimento. Não obstante, a economia industrial da região é ampla e diversificada, além da significativa expansão do setor terciário. Tais processos não lograram contrabalançar eficazmente o referido peso específico dos segmentos-líderes.

Por conseguinte, as perspectivas de geração, diversificação e melhora da qualidade dos empregos na região bem como as perspectivas de progressão da renda regional encontram-se limitadas. As políticas públicas sofrem as restrições decorrentes do efeito das oscilações econômicas provenientes dos dois segmentos estruturantes sobre a arrecadação e a transferência de recursos (especialmente o ICMS), afetando a capacidade das prefeituras de 
fornecer serviços públicos capazes de reduzir desigualdades sociais e melhorar a qualidade de vida. Além disso, há impactos negativos sobre o meio ambiente - uma riqueza natural da região, parcialmente degradada ao longo do tempo, com perda parcial de bens públicos, como a água e a vegetação - que se acentuam em períodos de crise econômica e social. Entre esses impactos, os mais graves referem-se a ocupações humanas nas áreas protegidas, em desconformidade com a legislação; e contaminação dos recursos hídricos e do solo urbano com dejetos, metais pesados e outras substâncias nocivas.

A documentação examinada e as entrevistas realizadas demonstraram a abrangência e a quantidade de iniciativas adotadas nos 15 primeiros anos do século XXI, com vistas ao desenvolvimento econômico regional. 0 tema da inovação esteve no centro das preocupações inerentes às iniciativas regionais pró-desenvolvimento. Realizaram-se esforços junto a universidades locais, órgãos federais e atores da própria região, visando a modernização e diversificação do setor produtivo. Iniciativas de qualificação e requalificação da força de trabalho, cooperação universidade-empresa e aperfeiçoamento do empresariado e das camadas gerenciais em métodos e técnicas de gestão multiplicaram-se, em escala municipal e regional.

Entretanto, a efetividade dessas ações foi muito limitada. Dentre as deficiências constatadas na pesquisa, observaram-se: (1) intermitências e descontinuidades, ligadas especialmente às mudanças políticas (prefeitos e/ou secretários); (2) interferências voltadas a jogos de prestígio e poder e não a eventuais desacordos de fundo nas finalidades ou nas iniciativas; (3) envolvimento diferenciado dos atores fundamentais, com maior participação dos sindicatos, presença em níveis distintos de algumas universidades, desniveis relevantes no comprometimento efetivo dos prefeitos, para além de discursos e eventos formais; (4) baixa participação e desinteresse majoritário no empresariado; (5) ausência de estrutura profissionalizada que incorporasse traquejo e memória das ações, sucessos e insucessos.

No tocante ao empresariado, observaram-se atitudes e percepções diferenciadas. A par de algumas participações muito minoritárias, a pesquisa identificou os seguintes padrões comportamentais: 1) imediatismo, desejo de resultados de curtíssimo prazo e falta de tempo alegada por grande parte dos pequenos e médios empresários; 2) bom domínio do "chão de fábrica" e das práticas produtivas em geral, em contraste com baixo teor estratégico e de planejamento nesse mesmo segmento; 3) expectativa de que a defesa de interesses empresariais regionais ficasse a cabo das empresas de grande porte, por sua vez totalmente desinteressadas em ocupar esse papel; 4) capacidade das empresas-líderes da região de articular-se diretamente às autoridades federais, individualmente ou por meio de suas associações de classe; 5) envolvimento eventual de algumas dessas empresas em poucas ações regionais para efeito de marketing regional, exceção feita à Braskem (operadora do Polo Petroquímico), mais comprometida.

Vale também observar que as empresas líderes, especialmente as montadoras de veículos e os grandes sistemistas, possuem departamentos de engenharia que, em abstrato, compõem um sistema de inovação regional. $\mathrm{Na}$ prática, entretanto, esses organismos atuam 
de forma estanque e sigilosa, não articulada entre si nem muito menos com o restante do tecido empresarial da região. Foi indicada, em algumas entrevistas, a realização de projetos de cooperação com universidades locais, todos eles estanques e imersos em sigilo. Receberam o nome de "projetos invisíveis" em uma das entrevistas (ibid., pp. 318-321).

\section{Periodização, avanços e desafios pendentes na construção do SRI}

A história da luta pela construção de um Sistema Regional de Inovação no Grande $A B C$ nas últimas três décadas pode ser periodizada como segue. Um primeiro período abrange os 11 anos que medeiam a instalação do Consórcio e a trágica morte do prefeito de Santo André, Celso Daniel (1991-2002). Nesse período, a região sofreu grandes dificuldades econômicas, sociais e ambientais. Em contrapartida, os atores regionais demonstraram grande criatividade política (Conceição, 2001 e 2008). Iniciativas locais tiveram abrangência nacional e até internacional. No primeiro caso, cita-se a Câmara Setorial Automotiva (1992-1993), experiência nacional de articulação entre as autoridades econômicas, os segmentos empresariais da cadeia produtiva automobilística e os sindicatos de trabalhadores, para delinear estratégias e políticas para esse setor (Arbix, 1996; Conceição, 2008). A Câmara Setorial Automotiva teve resultados positivos do ponto de vista do estímulo ao consumo e à produção de veículos automotores, com impactos benéficos no emprego regional.
No plano internacional, o protagonismo foi do Sindicato dos Metalúrgicos do $A B C$. Seus dirigentes visitaram as matrizes de empresas que haviam anunciado fechamento de plantas locais, com grande impacto negativo nos empregos e na renda regional. A Whirpool, controladora da Brastemp, a Ford Motor Company e a Volkswagen A.G. foram as principais. Houve solidariedade dos sindicatos dos países de origem e repercussão na imprensa. Os resultados foram positivos, mesmo quando o encerramento de atividades não foi revertido (caso da Brastemp).

Também é nessa época que surgem as instituições de articulação regional que destacaram a região. Ao Consórcio (1990), seguiram-se o Fórum da Cidadania do Grande $A B C$ (1994), a Câmara Regional do ABC (1997) e a Agência de Desenvolvimento Econômico do Grande ABC (1998). Sociedade civil, prefeitos, empresários, sindicatos e universidades buscavam, assim, defender a região da devastação socioeconômica e dialogar com as estratégias de desenvolvimento regional. Inúmeras atividades, fóruns e seminários ocorreram. 0 Consórcio, em especial, passou a exercer papel ativo na articulação de políticas públicas comuns entre os sete municípios, atuando, inclusive, junto aos governos estadual e federal. A Agência empreendeu algumas importantes ações entre elas, o início das discussões do que viria a ser o Projeto APL (Arranjo Produtivo Local), ${ }^{3}$ notadamente nos segmentos metalmecânico (Nogueira Neto et al., 2009; Zambanini, Bresciani e Oliveira, 2012) e plástico (Vieira, Lepore e Bresciani, 2008). A liderança de Celso Daniel nesse período foi inconteste.

Uma segunda etapa pode ser identificada na emergência do Governo Lula, estendendo-se 
até a eclosão da crise subprime e seu impacto no Brasil, especialmente no Grande ABC (20032008). Foi o período em que ações da União beneficiaram amplamente a região, como citado, destacando-se a ampliação do Polo Petroquímico, o estímulo à produção e aquisição de veículos automotores e a criação da Universidade Federal do $A B C$ - UFABC, com dois campi (Santo André e São Bernardo do Campo), além da implantação de campus local da Universidade Federal de São Paulo - Unifesp (em Diadema). Também é característico da ação federal nesse período - estendendo-se, de fato, até 2013 - um conjunto de iniciativas de política pública e criação de organizações governamentais com foco na inovação. ${ }^{4}$

Nesse período, em que pese a continuidade do Consórcio e da Agência - ao passo que os outros dois organismos se desvaneceram -, percebeu-se uma perda de vitalidade e de impulso nas ações da regionalidade. Ações já discutidas na etapa anterior mostraram muito esforço e pouco resultado. Destacam-se, acima de tudo, o Projeto APL e duas iniciativas voltadas a cadeias produtivas específicas. 0 primeiro deles foi o Projeto Centro de Serviços em Tecnologia e Inovação do Grande ABC-Cestec - parceria da Agência, Sebrae, Banco Interamericano de Desenvolvimento (BID) e o Centro Meccano da Região de Marche, Itália, no âmbito do convênio firmado com o BID, intitulado "Programa de Serviços Tecnológicos e Identificação de Novas Tendências de Mercado". Seu objetivo principal era promover e fortalecer o intercâmbio entre as empresas e as instituições geradoras de conhecimento científico e tecnológico para criar melhores condições locais de desenvolvimento produtivo das micro, pequenas e médias empresas (MPME).
0 segundo projeto específico relevante foi o Centro de Informação e Apoio à Tecnologia do Plástico - Ciap, sediado na Fundação Santo André, com a função de disseminar informações aos empresários sobre inovações em andamento no mercado, por meio de um boletim eletrônico. Oferecia consultoria, dispunha de laboratório e orientava empresários que vinham buscar soluções para gargalos tecnológicos.

Ambos os projetos possuíam interessante conceituação, atendiam necessidades regionais e conquistaram bons parceiros institucionais. Entretanto, seus resultados foram pífios - o primeiro não decolou, e o segundo teve alcance muito limitado e terminou bloqueado por questões de menor relevância. 0 ex-coordenador do Ciap, docente da Fundação Santo André, entrevistado, citou uma disputa menor pela cidade-sede do organismo, a partir da mudança na presidência da $A D E-G A B C$, de um prefeito para outro; a imposição de um gestor financeiro contraposto ao gestor técnico; escolhas baseadas apenas no critério do menor gasto, em detrimento do atendimento às finalidades de determinadas medidas para as quais havia dotação de recursos; e, por último, a não renovação das bolsas Finep que remuneravam os quatro técnicos integrantes do projeto, 0 que praticamente liquidou a experiência.

0 Projeto APL, o Cestec e o Ciap ocorreram no período marcado pelo vazio deixado por Celso Daniel. 0 esforço de alguns prefeitos, secretários municipais, técnicos e sindicalistas permitiu manter as ações citadas, em caráter parcial e descontínuo, mas não logrou ampliar o envolvimento dos segmentos sociais-chave, especialmente o empresariado. A região beneficiou-se das ações federais supracitadas de forma mais que tudo passiva, não tendo nelas se 
apoiado para avançar no desenvolvimento de um verdadeiro Sistema Regional de Inovação.

0 último trimestre de 2008 foi marcado por retração do crédito privado, envolvimento de grandes grupos econômicos brasileiros com a crise subprime e o claro início de fase recessiva, atingindo especialmente a indústria. 0 Grande $A B C$ foi uma das maiores caixas de ressonância desse impacto, com ameaças concretas à produção, ao investimento, ao emprego e à arrecadação tributária.

A reação imediata da região, com o Seminário "O $A B C$ do Diálogo e do Desenvolvimento" (11 e 12 de março de 2009), reunindo empresários, sindicatos, prefeitos, o governador paulista e ministros de Estado, foi o início da reversão da atuação passiva anterior. Esse período também marcava a chegada de prefeitos mais alinhados com o Governo Federal. Havia, portanto, suporte político na região para ações mais sintonizadas com o neodesenvolvimentismo em curso no âmbito nacional, ao mesmo tempo que a crise tornava urgente a retomada da proatividade regional.

Efetivamente, todo o ano de 2009 foi marcado por iniciativas derivadas daquele seminário. Grupos de trabalho (GT) foram constituídos e subdivididos tematicamente - o GT Automotivo, por exemplo, teve subgrupos relacionados a crédito, logística, engenharia e tecnologia, entre outros. 0 presidente do BNDES palestrou na região, e alternativas de viabilização do crédito público a empresas em dificuldades foram aventadas. Essas foram as principais ações encetadas à época.

A retomada robusta do crescimento econômico em 2010 (crescimento de 7,5\% do PIB, o maior da década) dissipou as preocupações e fez refluir o impulso proativo na região. Não obstante, desencadeou-se nova rodada de iniciativas dirigidas, principalmente, à criação de APL em diversos ramos de atividade, a partir de 2010. Iniciada com a criação do APL Ferramentaria pelas prefeituras de Diadema e São Bernardo do Campo, essa rodada prosseguiu, a partir de 2013, com o surgimento de 11 novos APLs, por iniciativa deste último município, sete dos quais em segmentos da indústria: defesa, químicos, autopeças, têxtil e confecções, gráficas; panificação e moveleiro (Conceição et al., 2015; São Bernardo do Campo, 2015b).

Com a retomada econômica, 0 anticlímax anterior à crise subprime retornou à região. $\mathrm{A}$ direção do esforço mencionado acima por um município, embora o mais avantajado na indústria regional, expressava a fragilidade da Agência, candidata natural à liderança nesse campo. 0 prefeito de São Bernardo dinamizou as atividades do Consórcio, nas três ocasiões em que o presidiu (2013, 2014 e 2016); contudo, isso só acentuou a distância entre os desempenhos das duas entidades regionais. A conjuntura econômica tornou-se progressivamente mais frágil no quadriênio seguinte, até o início de prolongada recessão no segundo semestre de 2014. Ao lado dos problemas econômicos pendentes, observou-se crescimento das importações, mesmo por empresas que aderiram ao Regime Automotivo Inovar-Auto, criado em 2013, com forte impacto na região. Apesar de a região do Grande $A B C$ ter alcançado alguns pontos favoráveis, como a inclusão da ferramentaria entre os setores estimulados, esta e outros segmentos tradicionais sofreram o impacto negativo da crescente importação de insumos.

A inércia empresarial seguiu sendo a tônica. Duas gestões da Agência sob liderança empresarial (2003-2005 e 2011-2013) não 
reverteram esse processo. Ao longo de sua trajetória, as diversas tentativas de articular empresas e universidades tiveram escassos resultados, principalmente em termos de adesão e prosseguimento. Nesse quadro, o resultado positivo no tocante à instalação da unidade fabril da Saab na região, no quadro de um esforço para desenvolver a cadeia produtiva de defesa na região - com todas as incógnitas ainda existentes -, é quase uma singularidade.

A esse respeito, cumpre esclarecer que 0 prefeito de São Bernardo do Campo (gestões 2009-2012 e 2013-2016) empreendeu grande esforço para atrair à região o vencedor da licitação internacional para fornecimento de caças supersônicos à $F A B$. A escolha, pelo Governo Federal, da Saab sueca, no final de 2014, teve como resposta o compromisso da empresa de instalar uma unidade fabril naquele município. Criou-se um APL de Defesa na região, coordenado pela prefeitura de São Bernardo, por meio da Secretaria de Desenvolvimento Econômico, Trabalho e Turismo (SDET), com a participação da $A D E-G A B C$. Notícias recentes davam conta da permanência daquela decisão, embora cercada de indefinições. ${ }^{6}$

Não obstante o anticlímax relativo à $A D E-G A B C$ e a continuidade da inércia empresarial, o Grande $A B C$ acumulou experiência, provavelmente inédita em âmbito nacional e bastante expressiva mesmo em relação a padrões internacionais, no tocante à articulação regional, envolvendo o poder público local, o setor privado e a sociedade civil organizada. Indubitavelmente, esse acúmulo representa uma alavanca expressiva para novos avanços. Como referido, é na área da infraestrutura e de algumas políticas públicas que o processo evoluiu mais. Mesmo nesses campos, houve diferenças significativas na interação com outras esferas da Federação brasileira. Nos anos 1990, a União e o estado de São Paulo emanavam diretrizes neoliberais e de estímulo (a primeira) ou omissão (o segundo) em face da guerra fiscal, desastrosas para a região, tendo como contrapartida, apenas parcial, a boa experiência da Câmara Regional articulada com o Estado. No período 2003-2014, com o novo nacional-desenvolvimentismo, a região alcançou resultados positivos na relação com a União, enquanto a interação com o Estado foi mais eventual e fraca.

No que tange ao esforço pelo desenvolvimento econômico, o foco em inovação, modernização e diversificação foi intenso, acoplando-se a ele algumas atividades-meio relacionadas, como qualificação profissional e capacitação gerencial e empresarial. Seminários, conferências, workshops, palestras e cursos foram frequentes, embora não tenham mantido ritmo regular ao longo do tempo da observação da pesquisa (2000-2015).

As duas "ondas" de criação de APLs citadas - o Projeto APL e, posteriormente, os APLs criados pela prefeitura de São Bernardo do Campo (no caso de ferramentaria, juntamente com Diadema) - tiveram níveis diferenciados de envolvimento da Agência. No primeiro caso, seu papel foi de protagonista; no segundo, de participante. A partir de 2015, ela assumiu a coordenação da maioria dos APLs da "segunda geração", mas o ritmo de funcionamento destes reduziu-se.

Pode-se considerar fruto da ação dos APLs citados a indicação (pela Agência) de 28 empresas da região como candidatas a fornecedoras da unidade da Saab a ser instalada em São Bernardo do Campo. É pouco provável que 
esse resultado fosse alcançado sem o conjunto de atividades voltadas à sensibilização da empresa sueca e das autoridades militares e governamentais em geral sobre o potencial e 0 interesse do Grande ABC; bem como, em sentido recíproco, à sensibilização do empresariado e demais atores da região para as oportunidades abertas nessa área. No mínimo, o número de empresas teria sido menor. Além disso, a própria decisão da Saab, de instalar uma unidade no Grande $A B C$, embora tivesse sido dialogada desde o início das articulações iniciadas pelo prefeito de São Bernardo, poderia não ter sido mantida, caso a região não tivesse se mobilizado, por meio do APL de Defesa do Grande $A B C$ e do próprio prefeito, nos contatos com o Governo Federal, as Forças Armadas, as instituições acadêmicas, lideranças empresariais e autoridades suecas; e, também, com o setor industrial ligado à Defesa no Brasil.

Outro importante resultado verificado, considerando-se as ações mais enfocadas na pesquisa citada (Anau, 2017), foi a realização de dez edições da Feira de Móveis da Rua Jurubatuba, conhecida pela concentração de lojas de móveis em São Bernardo do Campo, recebendo visitantes, inclusive, de outras cidades da Região Metropolitana de São Paulo. As Feiras de Móveis iniciaram-se em 2011, com forte estímulo e apoio da prefeitura. ${ }^{7}$ Em que pese um conjunto de fragilidades apontadas, elas criaram um hábito social e de consumo, dentro e fora do município de São Bernardo do Campo; e estreitaram relações entre concorrentes antes não propensos à ação colaborativa e entre atores vistos reciprocamente apenas como adversários no passado - o que possibilita novas iniciativas. 0 desinteresse da nova gestão municipal pode obviamente relativizar o peso desse legado, mas não o anula. 0 próprio itinerário anterior mostra que não se partiu da "estaca zero", mas conseguiu-se dar um salto de qualidade em relação a experiências antecedentes. As formas e as ações poderão ser distintas na próxima experiência; contudo, sua possibilidade é agora maior do que se não tivesse ocorrido essa sequência de eventos.

0 mesmo pode ser dito das demais ações efetivadas, que reforçam elemento assinalado em entrevista: ${ }^{8}$ parte do empresariado, embora minoritária, adquiriu consciência da necessidade e das possibilidades da ação colaborativa entre atores diversos, com vistas à promoção do desenvolvimento regional. 0 tema da inovação foi tratado de forma concreta e não apenas teórica. Acessos a instituições financeiras e a laboratórios, centros de pesquisa e de qualificação foram facilitados a empresas que, individualmente, não os teriam alcançado (ibid., p. 317). Outro entrevistado, ${ }^{9}$ menos otimista em relação às ações realizadas junto ao empresariado, esclareceu que, a despeito das fragilidades, o Grande $A B C$ beneficiou-se das atividades empreendidas na via da inovação e da articulação do setor produtivo com outros atores. No mínimo, sofreu menos danos nos períodos críticos do que teria sofrido, caso aquelas ações não tivessem sido efetuadas (ibid., pp. 318-321).

Além desses aspectos, a ampla gama de estudos, levantamentos e inventários realizados sobre a região do Grande $A B C$ já é, em si mesma, não apenas testemunho dos esforços realizados, mas também instrumento de autoconhecimento, interpretação e, inclusive, de elaboração de estratégias visando a reforçar os pontos fortes e suprir, atenuar ou compensar os pontos fracos da estrutura produtiva regional. 
Já o Parque Tecnológico - antigo propósito da região - chega ao final do período examinado com resultado ambíguo. A tentativa, proposta em 2009, de articular um polo multilocalizado, com parques específicos em alguns municípios, interligados e sem sobreposições, não logrou sucesso. Santo André e São Bernardo do Campo lançaram-se, então, à criação de seus parques individuais, a partir da saída do primeiro, que buscou articulação própria exclusiva com o Governo estadual, com quem possuía maior entrosamento político, à época. A inviabilização daquela proposta inicial foi uma demonstração da ineficácia da Agência, incumbida das articulações necessárias à sua concretização. Como afirmou o professor Bresciani em sua entrevista para a pesquisa em foco (Anau, 2017), a saída unilateral de Santo André deveria ter reforçado o papel da Agência, uma vez que o Consórcio ficava enfraquecido com a saída de um de seus membros do projeto. Todavia, a instituição não possuía densidade política e representatividade suficiente para assumir esse papel de liderança.

Além disso, o recente credenciamento de Santo André no Sistema Estadual de Parques Tecnológicos e a perspectiva, discutida na gestão da Agência encerrada em 2017, de torná-lo regional, inclusive transferindo sua própria sede para a área do Parque, abrem uma perspectiva inexistente até então. Se o setor privado for capaz de preservar e impulsionar a entidade, pode-se abrir uma oportunidade mais concreta para o avanço do Sistema Regional de Inovação do Grande ABC. As expectativas não são otimistas, em vista do perfil ideológico dos novos gestores municipais, além da conjuntura de crise econômica profunda, com forte impacto nas finanças públicas dos municípios.
Em todo caso, os demais atores podem exercer pressão positiva no sentido de impedir a perda desse propósito, hoje, paradoxalmente, mais factível, em termos institucionais, do que no período de abastança e de lideranças políticas mais comprometidas com o desenvolvimentismo regionalizado.

Finaliza-se este artigo com a indicação de possibilidades concretas de alavancar a inovação produtiva na região, decorrentes da própria pesquisa e dos elementos que ela trouxe à tona. A finalidade é o fortalecimento institucional e operacional da Agência de Desenvolvimento Econômico do Grande $A B C$, contribuindo para evitar o desfecho mais desfavorável da presente crise da entidade.

\section{Possibilidades concretas de ação e (re)organização - à guisa de sugestões}

A Agência enfrenta um cenário que torna impositiva a adoção de iniciativas ousadas para sua própria sobrevivência. No início de 2017, um questionamento do Tribunal de Contas do Estado (TCE-SP) levou o novo prefeito de São Bernardo do Campo e presidente do Consórcio a cancelar legalmente o financiamento público da entidade. Outros prefeitos seguiram essa atitude. Mais tarde, houve uma recomposição, mas a denúncia dos sindicatos, retrocitada, indica que as prefeituras estão de fato abandonando a instituição, o que confirma a impressão inicial de que a ação do TCE-SP serviu de pretexto para um propósito previamente definido. Ademais, a saída de Diadema agrava a situação do próprio Consórcio, entidade que, 
bem ou mal, cumpriu funções importantes na história regional, com mais efetividade que a Agência, da qual é membro constitutivo (respondendo por $49 \%$ de seu financiamento).

Faz-se necessário resgatar e assegurar a continuidade da ADE-GABC, com vistas a resguardar o patrimônio imaterial consubstanciado em experiências e levantamentos realizados ao longo de duas décadas e avançar na elaboração e implementação de estratégias regionais, rumo à efetivação de um Sistema Regional de Inovação. Um passo nessa direção deve ser a realização de um salto de qualidade no autoconhecimento de sua estrutura econômica, de seus esforços inovativos e de suas estatísticas socioeconômicas, de forma sistêmica.

As sugestões concretas listadas abaixo buscam dar consequência ao esforço de levantamento e interpretação da trajetória regional, realizado na pesquisa em que se fundamenta 0 presente artigo (Anau, 2017). Trata-se de possibilidades abertas pela própria trajetória, subjacentes ao acervo de experiências efetivadas. Sua oportunidade, no momento difícil vivido pela Agência, traduz o lado positivo da presente crise.

\section{a) Possibilidades e propostas de ação}

Vislumbram-se, primeiramente, duas iniciativas imediatas. A primeira é a compilação e organização das atas e publicações de todos os APLs que tiveram existência efetiva, a começar pelo metalmecânico e de plásticos. Uma compilação bem-feita, indexada por época e tema, teria possibilitado avançar mais na própria pesquisa citada; e servirá seguramente a outras posteriores, voltadas à mesma ordem de preocupações ou relacionadas a elas. Os APLs criados a partir de 2010 chegaram, em grande parte, a editar revistas próprias, imprimir atas e, em alguns casos, balanços de realizações, estes últimos elaborados pela SDET de São Bernardo do Campo. Cabe resgatar e recuperar esses materiais, compilá-los e indexá-los.

0 mesmo, com ainda maior ênfase, pode ser dito acerca dos diversos levantamentos estatísticos já produzidos sobre a região. Uma sistematização, com índice analítico e temático, metadados e esclarecimentos metodológicos, proporcionará uma visão histórica de numerosos indicadores socioeconômicos do Grande $A B C$, hoje dispersos. Adicionalmente, pode compor um módulo do sistema regional de informações que consta dos objetivos da Agência, mas que até hoje não se efetivou. Por sua própria característica, de terem sido elaborados por distintas instituições, seu armazenamento poderia ser descentralizado, mas um diretório unificado, atualizado com regularidade, situado na Agência ou em instituição por ela credenciada para esse fim, deverá dar acesso ao conjunto, atendendo a quantos venham a se interessar pelo tema, pelos mais diversos motivos - na área acadêmica, na mídia, nas entidades empresariais e sindicais, bem como entre consultores e investidores interessados na região.

A compilação proposta poderá melhor subsidiar os trabalhos de pesquisa acadêmica regional, citados como realizações positivas das universidades locais na entrevista do professor Minciotti, citada (ibid., p. 317). Tais pesquisas, em níveis diversos de complexidade - projetos de iniciação científica, dissertações, teses, elaboração de artigos científi$\cos -$, terão maior embasamento nas informações compiladas e poderão avançar mais na interpretação da problemática regional e na proposição de ações e políticas para a região. 
A própria compilação pode ser realizada por instituições acadêmicas do Grande $A B C$, a partir de parceria com a Agência.

No plano da estratégia de desenvolvimento regional, o principal esforço deve ser o de coordenar os diversos atores para um processo de desenvolvimento regional focado na construção efetiva de um Sistema Regional de Inovação. Destacam-se, a partir do histórico e das constatações da pesquisa, alguns possíveis eixos desse processo:

- cooperação institucional frequente entre empresas e universidades em pesquisa, desenvolvimento, inovação, solução de gargalos tecnológicos, mercadológicos e organizacionais, conectando os atores relevantes para tanto;

- implementação e coordenação do parque tecnológico em Santo André, com caráter regional, tornando permanente o processo citado no item anterior;

- organização, atualização e disseminação de informações relevantes sobre:

a) oportunidades de financiamento e de negócios (por exemplo, em editais nos três níveis federados);

b) linhas de crédito;

c) programas e estímulos fiscais;

d) eventos, seminários e oficinas úteis em termos técnicos e/ou de oportunidades de mercado;

e) feiras de negócios e workshops, incluindo a divulgação de listas e mostruários de compras de insumos pelas grandes empresas da região e de regiões vizinhas para estimular possíveis fornecedores no próprio Grande $A B C$;

- oferta de serviços de orientação e apoio para a obtenção dos serviços e para o aproveitamento das oportunidades indicadas no item anterior;
- realização de ações continuadas de qualificação profissional e de capacitação empresarial, planejadas de acordo com necessidades e oportunidades identificadas com regularidade, em interação entre os atores regionais (Agência, estruturas de apoio ao empreendedorismo, sindicatos, Sistema S, Centrais de Trabalho e Renda, secretarias municipais de desenvolvimento econômico);

- implementação efetiva de planos e ações de marketing regional, apoiados em informações sistematizadas sobre o Grande $A B C$ - organizadas em banco de dados regional com atualização sistemática -, para atrair novos empreendimentos industriais, de serviços e do terciário avançado;

- plano continuado de comunicação e diálogo com o setor empresarial, especialmente no tocante às micro, pequenas e médias empresas da região, buscando informá-las regularmente das finalidades, atividades e oportunidades, da composição e dos fóruns de decisão, de modo a criar um canal permanente de motivação desse segmento econômico para estreitar sua relação com a Agência;

- articulação constante com fontes de financiamento privadas, públicas, multilaterais e do Terceiro Setor, para viabilizar programas e linhas de financiamento associados às finalidades acima.

A condição para o sucesso desses propósitos será o envolvimento em maior escala do setor produtivo com a Agência, os APLs e o conjunto de iniciativas e projetos. Para tanto, um redesenho institucional da Agência é indispensável, em processo dialógico entre seus componentes. 0 empoderamento do setor privado - para além da indicação de diretores 
dele provenientes - é imperativo para a sobrevivência da instituição. Se o histórico levantado anteriormente já apontava nessa direção, fatores mais recentes e imediatos tornaram-na imprescindivel e urgente.

b) Propostas de reorganização da Agência

A nova situação criada no início de 2017, com a retirada dos recursos das prefeituras, põe em risco imediato a sobrevivência da entidade. Entretanto, ela pode, por isso mesmo, ser o estopim que deflagre esse amplo diálogo. 0 enfraquecimento do próprio Consórcio, a partir da saída de Diadema, anunciada em julho de 2017, torna ainda mais remota a possibilidade de dinamização da ADE-GABC por iniciativa das prefeituras. Faz-se imprescindível transformar uma crise de maiores proporções em oportunidade de mudança para nova estrutura institucional. Mudança esta que deve expressar novas relações entre os atores, novas metas e novos métodos organizacionais e de ação, bem como impedir a perda da rica experiência desenvolvida nas últimas décadas.

A governança da Agência deve ser completamente reestruturada, nas condições particularmente difíceis deste final da segunda década do século XXI. 0 elemento-chave dessa reestruturação deve ser o empoderamento das principais organizações representativas do empresariado e dos trabalhadores. A trajetória percorrida e seu resgate na pesquisa (ibid.) não deixam lugar a dúvidas de que o maior gargalo se encontra no segmento empresarial. A ausência dos Ciesps não pode mais ser vista como lacuna a ser superada no futuro.

A título de esclarecimento sobre esse tema, os quatro Ciesps da região retiraram-se da Agência em princípios da década de 2000. As Associações Comerciais, que os acompanharam, retornaram à entidade, mas os Ciesps declararam apoiá-la sem participar. 0 argumento à época era o baixo rendimento da entidade. 0 problema de fundo era a pretensão do empresariado de exercer diretamente 0 comando da Agência, adiante da proposta de reeleição do prefeito Celso Daniel para sua direção. Posteriormente, houve, como dito, duas experiências de gestão por lideranças empresariais: um diretor da Braskem e um presidente de Associação Comercial e Industrial.

As Associações Comerciais não dão conta da representação do empresariado industrial do Grande ABC. Todavia, podem ser importante agente de atração deste último. Da mesma forma, as associações nacionais de segmentos industriais, que se mostraram participativas nos APLs, podem ser outro fator de motivação dos Ciesps para assumirem uma ADE-GABC autônoma em relação às prefeituras. 0 mesmo pode ser dito de certos sindicatos patronais - especialmente, embora não exclusivamente, de caráter regional - que adquiriram experiência com o tema do desenvolvimento regional por meio dos APLs, como o SIMABC - Sindicato da Indústria de Móveis de São Bernardo do Campo e Região no APL Moveleiro ou o Sindicato e a Associação das Indústrias Gráficas do Grande ABC e Baixada Santista (Singrafs-Assingrafs) no respectivo APL. Certas entidades empresariais com tradição local, como a Associação dos Construtores, Imobiliárias e Administradoras do Grande $A B C$ (ACIGABC), podem ser convencidas a compor 0 esforço de atração dos Ciesps, a partir da constatação de que o fortalecimento da estrutura produtiva regional produz externalidades positivas para todos os ramos de negócios.

A ação das entidades supracitadas, das lideranças acadêmicas, dos sindicatos 
de trabalhadores e de personalidades de relevância social e política na região - como parlamentares das esferas federal e estadual, eventuais lideranças da mídia regional e representantes da sociedade civil preocupados com o futuro da região - deve ser a alavanca para a reorganização da entidade sob controle privado, dirigindo-se especificamente aos Ciesps. Caberá a estes, necessariamente, maior protagonismo na nova estrutura organizacional e na definição dos gestores operacionais da entidade. A partir de seu envolvimento, a parceria com os sindicatos e as universidades poderá ser redefinida e dinamizada, com base em projetos estratégicos de impulsionamento do Sistema Regional de Inovação.

Uma vez reestruturada, a entidade deverá elaborar e propor uma agenda de aproximação e cooperação com dois atores-chave. 0 primeiro são as empresas-líderes (uma das quais, a Braskem, pode ser um aliado no esforço de aproximação com as demais, especialmente montadoras e grandes empresas dos segmentos químico e metalúrgico). Essa cooperação deve ocorrer preferencialmente em projetos e parcerias específicas que possam interessá-las, como capacitação de fornecedores e prestadores de serviços, ou participação no Parque Tecnológico em projetos de fronteira tecnológica, respeitados os requisitos de sigilo. 0 segundo ator-chave são os prefeitos, agora sob formas distintas da que vigorou até o presente. De fato, estes não seriam mais membros efetivos, cabendo considerá-los possíveis parceiros em projetos específicos e participantes de um fórum mais amplo em que se discutam diagnósticos e estratégias para o desenvolvimento econômico e a inovação no Grande ABC. Também é recomendável abrir espaço para a participação dos secretários municipais de desenvolvimento econômico em atividades e fóruns mais específicos - como o exemplo, já citado, da definição periódica de prioridades de qualificação profissional e capacitação empresarial, resultando em parcerias entre a ADE-GABC, instituições especializadas e as respectivas secretarias nas ações daí decorrentes.

Ao longo do tempo, essas secretarias, especificamente, têm a vocação de estimular uma reaproximação das prefeituras com a Agência, agora definida como órgão sob hegemonia privada, no critério tripartite acima explicitado (empresariado, sindicatos e universidades proposta inicial para o diálogo entre os atores relevantes). 0 Parque Tecnológico e os APLs são exemplos mais abrangentes em que a cooperação público-privada é altamente recomendável. A eles somam-se algumas linhas de ação permanente da ADE-GABC (marketing regional, articulação junto a órgãos federais e estaduais de fomento), bem como certos projetos específicos. Esse contexto indica a conveniência de uma aproximação gradual com as administrações públicas locais, mantendo o predomínio privado na instituição.

Formalmente, conforme a proposta sugerida, poder-se-ia constituir um conselho tripartite - empresários, sindicatos e universidades -, a partir de assembleia periódica que discuta os grandes eixos de atuação, em que cada parte indique seus representantes ao Conselho. Em vista do histórico, parece adequada uma composição diferenciada, com maior peso relativo do empresariado (algo como 40\%; 30\%; 30\%, a título de exemplo). Esse órgão, por sua vez, definiria a estrutura funcional da Agência, com uma equipe profissional enxuta, não sujeita ao rodízio político, encarregada da construção de 
uma expertise e memória coletiva e institucional. 0 programa de ação seria definido pela assembleia e detalhado, acompanhado e corrigido pelo Conselho, obrigado às necessárias prestações de contas à assembleia.

Evidentemente, isso implica redefinição, também, das fontes de financiamento permanente da Agência. Convênios, parcerias, captação de recursos de agências públicas, privadas, multilaterais e do Terceiro Setor, projetos compartilhados, obtenção de patrocínios, venda de publicidade em possíveis e desejáveis publicações, bem como a cotização dos participantes - em parte, talvez, na forma de aporte econômico, como, por exemplo, na contratação e alocação da equipe profissional e de itens físicos como computadores -, serão fundamentais. Propõe-se que especialistas da área acadêmica e do setor empresarial (eventualmente, com consultores contratados ad hoc) formulem o projeto de financiamento, acoplado às ações e aos programas fundamentais da Agência.

\section{Considerações finais}

A relevância industrial do Grande $A B C$ no século XX deveu-se a fatores não relacionados à ação deliberada de seus agentes políticos, sociais e econômicos com foco no desenvolvimento regional. Somente a partir da década perdida (anos 1980) e da era de hegemonia neoliberal (1990-2002), com a forte incidência das crises econômicas de âmbito nacional na região, desencadeou-se o esforço pela articulação regional e pela defesa da região, desdobrando-se na perspectiva estratégica de impulsionar por iniciativa própria o desenvolvimento, por meio da modernização e da diversificação de sua base produtiva.

Esse esforço alcançou resultados muito aquém dos pretendidos. Nas três décadas transcorridas desde a fundação do Consórcio Intermunicipal Grande $A B C$, a região seguiu refletindo com muita intensidade os impulsos emanados da conjuntura macroeconômica e da política econômica nacional, ao passo que as ações empreendidas pelos atores locais com aquele objetivo foram pouco eficazes. Não obstante, acumulou-se expressiva experiência ao longo dos vinte anos de existência da Agência de Desenvolvimento Econômico do Grande $A B C$, completados em 2018. Essa instituição concentrou as expectativas locais no sentido de coordenar esforços dos atores da região rumo a inovação, modernização e diversificação da indústria e dos serviços. Inúmeras iniciativas e projetos foram encetados sob sua coordenação. No entanto, observa-se que os projetos sofreram solução de continuidade e tiveram grande dificuldade de envolver o grosso do empresariado local, ator-chave para o desenvolvimento econômico regional. Dada sua fragilidade intrínseca, em certos momentos, já referidos, sua ação foi eclipsada pela das Secretarias de Desenvolvimento Econômico de Diadema e de São Bernardo do Campo. Essa fragilidade mostrou-se especialmente no fato de seu papel na concretização do Polo Tecnológico - projeto que condensava o essencial da estratégia de desenvolvimento baseado na inovação - ter sido inócuo.

No momento em que a ADE-GABC atravessa uma crise com potencial destrutivo, os atores regionais estão confrontados a um desafio tão grave quanto aquele que deu origem à entidade. 0 acúmulo de experiências, não 
apenas no tocante à documentação, aos projetos e às ações, mas também à articulação entre atores diversos e mesmo conflitantes, pode ser transformado em alavanca para uma superação positiva da crise, processo em que o Grande $A B C$ se destacou nas décadas difíceis de 1980 e 1990.

Em vista da renúncia dos prefeitos de assumir papel ativo na articulação regional e dos impasses, inclusive orçamentários, enfrentados pela Agência, e levando também em conta a história conflitante da entidade com as representações locais da indústria, a saída mais factível é sua efetiva encampação pelo setor privado, com os três componentes que historicamente a constituíram, além dos governos locais (por meio do Consórcio): associações empresariais, sindicatos e universidades. A relação com os prefeitos terá que ser redesenhada, estabelecendo fóruns comuns e parcerias, porém com sua exclusão do núcleo de tomada de decisões operacionais e orçamentárias. Além disso, o redesenho e a reprogramação de atividades devem atender a duas preocupações adicionais: atrair, motivar e comprometer parcelas expressivas do pequeno e médio empresariado do Grande $A B C$ e buscar o diálogo e a parceria com as empresas-líderes dos segmentos estruturantes da economia regional.

0 critério da exclusividade privada não é proposto por princípio, mas por consideração à história concreta e à conjuntura específica. 0 conflito com os Ciesps consistiu em luta pelo poder na entidade. Rejeitada sua pretensão, aqueles órgãos representativos da indústria regional recusaram-se a participar. A presença dos prefeitos ao longo do processo teve peso real mais acentuado que os formais $49 \%$ da definição regimental. Diversos conflitos especí- ficos e problemas operacionais decorreram daí, no ambiente rarefeito resultante da ausência do principal ator, ao qual era dirigido o propósito da instituição. Vejam-se, por exemplo, as vicissitudes do Ciap, conforme o relato de seu coordenador. 0 projeto tinha boa concepção, contava com local, técnicos, equipamento e destinava-se a um segmento necessitado de apoio - o terceiro escalão da indústria do plástico. Parafraseando Anau (2017), encontrava-se aí concretizado o pacote neoschumpeteriano completo. A baixa adesão desse segmento, refletindo uma cultura arraigada, já seria um desafio. Seu agravamento por conflitos de baixo teor estratégico, mais relacionados a disputas de prestígio e poder, acabou por esvaziar o projeto.

Foi praticamente consensual, entre os entrevistados na pesquisa (ibid.) a constatação de que o peso dos prefeitos era excessivo na Agência. No presente, contar com a participação dos executivos municipais tornou-se incogitável. Dessa forma, o setor privado, com seus três componentes mencionados, tem diante de si a disjuntiva: assumir efetivamente a entidade, preenchendo a lacuna deixada pela indústria, ou deixá-la perecer, levando consigo 0 acervo de experiências construídas e desistindo de adotar atitude proativa no desenvolvimento regional.

Ressalte-se que o componente acadêmico não é integralmente privado. Seu membro mais assíduo foi a USCS, autarquia municipal. A Fundação Santo André, outra instituição de ensino superior (IES) pública local, teve momentos de envolvimento, como é o caso especialmente do Ciap. Mais recentemente, a UFABC demonstrou grande propensão a cooperar com as iniciativas locais voltadas 
à inovação, inclusive em projetos da Agência como o Birô de Engenharia proposto pelo APL de Ferramentaria. Embora não tenha vingado, por depender de recursos federais, esse projeto indicou o forte interesse da UFABC em superar seus próprios limites - a rigidez jurídico-burocrática inerente a uma IES federal - e incorporar-se ao esforço regional pela inovação. Sua Agência de Inovação é atuante e institucionaliza esse propósito. Assim, o próprio segmento acadêmico mescla instituições privadas - algumas confessionais, como a $\mathrm{FEI}^{10}$ e a Universidade Metodista - e públicas. Além disso, os chamados "projetos invisíveis" das montadoras envolvem parcerias com universidades privadas especialistas nas Engenharias. Assim, um dos objetivos adicionais, no processo de resgate e reorganização da Agência, deve ser o de incorporar permanentemente mais IES da região, especialmente aquelas com maior ênfase tecnológica.

0 resgate da $A D E-G A B C$, com seu redesenho e reorientação, requer um adequado plano de ação com objetivos e metas claros, uma equipe permanente (ainda que enxuta) e fontes diversificadas de recursos. Esses elementos-chave incumbem aos principais atores constitutivos da "nova" Agência de Desenvolvimento Econômico do Grande ABC. Esta é sua missão central na presente quadra histórica.

\section{[I] https://orcid.org/0000-0003-3340-9729}

Universidade Municipal de São Caetano do Sul, Escola de Negócios, Curso de Ciências Econômicas. São Caetano do Sul, SP/Brasil. rovitan@gmail.com

\section{Notas}

(1) Ver Conceição (2017); e ainda, o alerta dos sindicatos, em: http://www.abcdoabc.com.br/abc/ noticia/sindicatos-querem-deixar-consorcio-agencia-gabc-59003. Acesso em: 4 jan 2018.

(2) Ver também Lundvall et al. (2002). Entre os autores que adaptaram o conceito à realidade brasileira, destacam-se Cassiolato e Lastres (2005).

(3) “Arranjo Produtivo Local, ou APL, representa a aproximação e o diálogo entre empresas de um mesmo território para uma ação coordenada, visando ao crescimento da produção e da competitividade. O APL contribui para levantar problemas comuns às empresas e para elaborar e executar políticas (públicas e privadas) que promovam, de modo duradouro, o fomento da atividade produtiva no território. [...] também costumam participar associações representativas das empresas, universidades, instituições de ensino técnico e gestão pública. O formato segue o modelo internacionalmente conhecido como 'tríplice hélice' (setor produtivo, universidades e poder público). Em regiões como a do Grande $A B C$, onde o movimento sindical é forte e propositivo, o sindicato de trabalhadores igualmente costuma participar e até mesmo liderar os APLs" (Conceição et al., 2015, p. 272). 
(4) Dentre as principais ações nessa linha, destacam-se a criação da Agência Brasileira de Desenvolvimento Industrial (ABDI), em 2004; as Leis da Inovação, de 2004, e do Bem, de 2005; a criação da Empresa Brasileira de Pesquisa e Inovação Industrial (Embrapii), em 2013; o fortalecimento da Financiadora de Estudos e Projetos (Finep); e o estímulo à criação de Agências de Inovação nas universidades públicas, visando à cooperação com o setor privado em pesquisa aplicada e desenvolvimento.

(5) De 1999 a 2018, a ADE-GABC foi dirigida por seis prefeitos, dois empresários, um sindicalista e um gestor acadêmico.

(6) Conferir: http://www.dgabc.com.br/Noticia/2790398/saab-anuncia-diretor-em-s-bernardo-masnao-revela-endereco). Ver, também, Anau (2011).

(7) O evento possui site próprio: http://www.ruajurubatuba.com.br/index.php. Acesso em: 4 jan 2018.

(8) Professor Silvio Minciotti, ex-reitor da Universidade Municipal de São Caetano do Sul (USCS), ex-secretário executivo da Agência e atual secretário de Desenvolvimento Econômico, Trabalho, Turismo, Tecnologia e Inovação de São Caetano do Sul.

(9) Professor Luís Paulo Bresciani, ex-secretário de Desenvolvimento em Santo André e Diadema, ex-secretário executivo do Consórcio e docente da USCS e FGV.

(10) Fundação Educacional Inaciana, anteriormente Faculdade de Engenharia Industrial.

\section{Referências}

ALESP - Assembleia Legislativa do Estado de São Paulo (2011). São Bernardo do Campo, cidade do móvel e do automóvel. Disponível em: https://www.al.sp.gov.br/noticia/?id=312958. Acesso em: 30 jan 2018.

ANAU, R. V. (2011) (org.). São Bernardo do Campo, Grande ABC: nova fronteira da indústria de defesa. São Bernardo do Campo, MP Editora. Disponível em: http://defesaeseguranca.com.br/wpcontent/uploads/cadernos-sao-bernardo-vol021.pdf. Acesso em: 12 jan 2018.

(2017). Desenvolvimento, inovação e aprendizagem: avaliação da trajetória do Grande ABC. Tese de Doutorado. São Bernardo do Campo, Universidade Federal do ABC.

ARBIX, G. (1996). Uma aposta no futuro: os primeiros anos da Câmara Setorial da Indústria Automobilística. São Paulo, Scritta.

(2005). Inovações, padrões tecnológicos e desempenho das firmas industriais brasileiras. IPEA, Estudos e Pesquisas, n. 96, Rio de Janeiro.

BRENNER, N. (2010). A globalização como reterritorialização: o reescalonamento da governança urbana na União Europeia. Cadernos Metrópole. São Paulo, v. 12, n. 24, pp. 535-564.

BRENNER, N. e THEODORE, N. (2003). Spaces of neoliberalism: urban restructuring in North America and Western Europe. Hoboken, NJ (USA), Wiley-Blackwell. 
CASSIOLATO, J. E. e LASTRES, H. (2005). Sistemas de Inovação e desenvolvimento - as implicações de política. São Paulo em Perspectiva. São Paulo, v. 19, n. 1, pp. 34-45.

CONCEIÇÃO, J. J. (2001). As fábricas do ABC no olho do furacão: a indústria de autopeças e a reestruturação da cadeia de produção automotiva nos anos 90. Dissertação de Mestrado. São Caetano do Sul, Instituto Municipal de Ensino Superior de São Caetano do Sul.

(2008). Quando o apito da fábrica silencia: sindicatos, empresas e poder público diante do fechamento de indústrias e da eliminação de empregos na Região do $A B C$. São Bernardo do Campo, MP Editora.

(2017). Sobre a Agência de Desenvolvimento do Grande ABC. ABCD Maior. Disponível em: http://blogjeffdac.blogspot.com.br/2017/02/sobre-agencia-de-desenvolvimento.html. Acesso em: 9 jan 2018.

CONCEIÇÃO, J. J.; KLINK, J. J.; OLIVEIRA, N. e ANAU, R. V. (2015). A cidade desenvolvimentista. Crescimento e diálogo social em São Bernardo do Campo, 2009-2015. São Paulo, Editora Fundação Perseu Abramo.

COSTA, E. (2007). Políticas públicas e o desenvolvimento de arranjos produtivos locais em regiões periféricas. Tese de Doutorado. Campinas, Universidade Estadual de Campinas.

FREEMAN, C. e SOETE, L. (2008). A economia da inovação industrial. Campinas, Editora da Unicamp.

JESSOP, B. (2000). The crisis of the national spatio-temporal fix and the tendential ecological dominance of globalizing capitalism. International Journal of Urban and Regional Research, v. 24, n. 2. Oxford (UK).

KLINK, J. J. (2000). Reinventando o planejamento regional em um contexto de restruturação econômica local: o caso da Região do Grande ABC. IMES, Caderno de Pesquisa, v. 2, pp. 23-29, São Caetano do Sul.

(2001). A Cidade-Região. Regionalismo e reestruturação no Grande ABC Paulista. Rio de Janeiro, DP\&A Editora.

(2003). O novo regionalismo à maneira do $A B C$ : em busca de uma economia regional de aprendizagem. CEBRAP, Caderno de Pesquisa, v. 8, pp. 1-7.

(2011). Os territórios da inovação. Retomando o debate (normativo) sobre a experiência do ABC Paulista (São Paulo). Contemporâneos: Revista de Artes e Humanidades (Online), v. 9, pp. 1-17. Disponível em: http://www.revistacontemporaneos.com.br/n9/dossie/territorios-inovacao.pdf. Acesso em: 29 jan 2018.

LUNDVALL, B.; JOHNSON, B; ANDERSEN, E. S. e DALUM, B. (2002). National systems of production, innovation and competence building. Elsevier, Research Policy, v. 31, pp. 213-231.

LUNDVALL, B.; VANG, J.; JOSEPH, K. J. e CHAMINADE, C. (2013). “Bridging innovation system research and development studies: challenges and research opportunities. Papers in Innovation Studies". CIRCLE, Center for Innovation, Research and Competences in the Learning Economy, Lund University. Disponível em: http://swopec.hhs.se/lucirc/abs/lucirc2013_033.htm. Acesso em: 17 jul 2017.

NELSON, R. e WINTER, S. (2005). Uma teoria evolucionária da mudança econômica. Campinas, Editora da Unicamp. 
NOGUEIRA NETO, M. de S. et al. (2009). APL de Ferramentaria da Região Metropolitana do ABC Paulista: prospecção das principais necessidades. In: XXIX ENCONTRO NACIONAL DE ENGENHARIA DE PRODUÇÃO - A Engenharia de Produção e o Desenvolvimento Sustentável: Integrando Tecnologia e Gestão. Anais... Salvador. Disponível em: http://www.abepro.org.br/biblioteca/enegep2009_ tn_sto_091_615_13519.pdf. Acesso em: 29 jan 2018.

PLONSKI, G. A. (2005). Bases para um Movimento pela Inovação Tecnológica no Brasil. São Paulo em Perspectiva, v. 19, n. 1, pp. 25-33. Disponível em: http://www.scielo.br/pdf/spp/v19n1/ v19n1a02.pdf. Acesso em: 29 jan 2018.

RODRIGUES, I. J.; RAMALHO, J. R. e CONCEIÇÃO, J. J. (2009). Reestruturação industrial, sindicato e território: alternativas políticas em momentos de crise na Região do $A B C$ em São Paulo, Brasil. Revista Crítica de Ciências Sociais, v. 85, pp. 147-167.

SÃO BERNARDO DO CAMPO (2015) - Prefeitura (PMSBC). Cadastro Geral das Indústrias. São Bernardo do Campo. Disponível em: http://www.cgi.saobernardo.sp.gov.br/cgi-sbc/. Acesso em: 29 jan 2018.

SÃO BERNARDO DO CAMPO (2015b)/ SECRETARIA DE DESENVOLVIMENTO ECONÔMICO, TRABALHO E TURISMO SDET/PMSBC. Página SDET do Facebook ${ }^{\circledR}$. "Política industrial e APL de Defesa". Disponível em: https://www.facebook.com/DesenvolvimentoSBC/. Acesso em: 29 jan 2018.

SÃO BERNARDO DO CAMPO (2015c) (Prefeitura). "Da produção de carvão a Capital do Móvel". Disponível em: http://www.saobernardo.sp.gov.br/home/-/asset_publisher/YVwaH6UqAMbt/ content/da-producao-de-carvao-a-capital-do-movel/maximized. Acesso em: 30 jan 2018.

VIEIRA, R. B.; LEPORE, W. e BRESCIANI, L. P. (2008). “O Projeto APL Plásticos e a Agência de Desenvolvimento Econômico do Grande ABC: a Competitividade Empresarial no foco das ações promovidas pela Organização da Sociedade Civil para a promoção de Desenvolvimento Regional”. In: ANPAD, ENCONTRO DE ADMINISTRAÇÃO PÚBLICA E GOVERNANÇA. Salvador.

VILHA, A. M.; FUCK, M. P. e BONACELLI, M. B. (2013). “Aspectos das trajetórias das políticas públicas de CT\&I no Brasil”. In: MARCHETTI, V. (org.). Políticas públicas em debate. Santo André, MP Editora.

VIOTTI, E. B. (2008). "Brasil: de política de C\&T para política de inovação? Evolução e desafios das políticas brasileiras de ciência, tecnologia e inovação". In: CENTRO DE GESTÃO E ESTUDOS ESTRATÉGICOS (CGEE). Seminário Internacional - avaliação de políticas de ciência, tecnologia e inovação: diálogo entre experiências internacionais e brasileiras. Brasília.

ZAMBANINI, M. E.; BRESCIANI, L. P. e OLIVEIRA, T. E. (2012). Inovação, cooperação e relações entre empresas: um estudo sobre a construção do Arranjo Produtivo Metalmecânico no Grande ABC. Ensaios FEE, v. 33, n. 2, pp. 483-512, Porto Alegre. Disponível em: http://repositorio.uscs.edu.br/ bitstream/123456789/932/2/2440-16657-1-PB.pdf. Acesso em: Acesso em: 25 jan 2018.

Texto recebido em 25/mar/2018

Texto aprovado em 30/jul/2018 